(C) 1998 OPA (Overseas Publishers Association) N.V.

Published by license under the Gordon and Breach Science Publishers imprint. Printed in India.

\title{
ENRICHMENT OF THE MANGANESE CONTENT BY WET HIGH INTENSITY MAGNETIC SEPARATION FROM CHIKLA MANGANESE ORE, INDIA
}

\author{
G.V. RAO*, B.K. MOHAPATRA and A.K. TRIPATHY \\ Regional Research Laboratory, Bhubaneswar, Orissa 751013, India
}

(Received 22 July 1997; Accepted 5 September 1997)

\begin{abstract}
Manganese ores from Chikla region, Bhandara district, Maharastra, India, by and large are low and medium grade types and need beneficiation to utilise them in ferromanganese industry. Isodynamic separation followed by chemical characterisation of ores from this region indicated their susceptibility to $\mathrm{Mn}$ enrichment. Details of characterisation, heavy media and magnetic separation studies carried out on a medium grade manganese ore, containing $44 \% \mathrm{Mn}, 7.8 \% \mathrm{Fe}$ and $22 \%$ acid insolubles, from the Chikla region are presented. By processing the material on a wet high intensity magnetic separator, a product with $51 \% \mathrm{Mn}$ at $95 \%$ recovery could be obtained.
\end{abstract}

Keywords: Manganese ore; $\mathrm{Mn} / \mathrm{Fe}$ ratio; Ferromanganese; Magnetic separation

\section{INTRODUCTION}

The estimated in-situ reserves of the manganese ores in India are of the order of 370 million tonnes, with recoverable reserves of about 177 million tonnes [1]. The grades suitable for various industries and the total manganese ore reserves are given in Table I. The domestic consumption pattern of manganese ore during 1990-1993 is given in Table II. The major manganese ore consumption is by ferroalloys and iron and steel industries in the country. Out of the 24 ferromanganese units in the country, 10 units are in the organised sector and the rest

\footnotetext{
* Corresponding author.
} 
TABLE I Reserves of manganese ore

\begin{tabular}{lrrrr}
\hline Grade & \multicolumn{3}{c}{ Recoverable reserves, in } & 000 tonnes (as on 1.4.1990) \\
\cline { 2 - 5 } & Proved & Probable & Possible & \multicolumn{1}{c}{ Total } \\
\hline All India total & 28,567 & 41,794 & 106,116 & 176,477 \\
Battery/chemical & 1,387 & 782 & 827 & 2,996 \\
Ferromanganese & 9,706 & 5,953 & 5,722 & 21,381 \\
Medium & 7,528 & 5,056 & 9,923 & 22,507 \\
BF & 7,895 & 16,951 & 33,237 & 58,083 \\
Ferromanganese and & 47 & 1,174 & 3,582 & 4,803 \\
$\quad$ medium, mixed & & & & \\
Medium and BF mixed & 627 & 2,860 & 2,186 & 5,673 \\
Ferromanganese, & 56 & 618 & 1,780 & 2,454 \\
$\quad$ medium and BF mixed & & & & \\
Ferromanganese and BF & 787 & 1,707 & 8,633 & 11,127 \\
Others & 15 & 12 & - & 27 \\
Unclassified & 471 & 6,082 & 37,351 & 43,904 \\
Not known & 48 & 598 & 2,876 & 3,522 \\
\hline
\end{tabular}

TABLE II Manganese ore domestic consumption pattern

\begin{tabular}{lrrr}
\hline Industry & $\begin{array}{c}1990-91 \\
\text { Tonnes }\end{array}$ & $\begin{array}{c}1991-92 \\
\text { Tonnes }\end{array}$ & $\begin{array}{r}1992-93 \\
\text { Tonnes }\end{array}$ \\
\hline Alloy steel & 200 & 100 & 100 \\
Battery & 25,100 & 26,400 & 24,200 \\
Chemical & 2,800 & 2,600 & 2,700 \\
Ferro alloys & 616,200 & 670,600 & 641,200 \\
Iron and Steel & 572,500 & 605,300 & 663,200 \\
Lead-zinc smelters & 2,700 & 2,600 & 2,600 \\
Others (e.g., ceramics, foundry, & 100 & 100 & 200 \\
glass \& paint industries) & & & \\
\hline
\end{tabular}

14 units are in small scale sector with total capacity of about 0.488 million tonnes per year [2]. The location, capacity and the grade of manganese ore being used in the 10 units of the organised sector [3] is given in Table III.

The manganese ore requirement for the iron and steel industry is assessed at 1.065 million tonnes, based on the envisaged hot metal production target of 21.3 million tonnes by nine major pig iron plants. The blast furnaces of the steel plants in India consume manganese ore with $25-30 \% \mathrm{Mn}, 5-25 \% \mathrm{SiO}_{2}, 5-8 \% \mathrm{Al}_{2} \mathrm{O}_{3}, 14-26 \% \mathrm{Fe}$ and $0.074-$ $0.34 \% \mathrm{P}$ and do not face any serious problem due to availability of adequate ore meeting the above specification. 


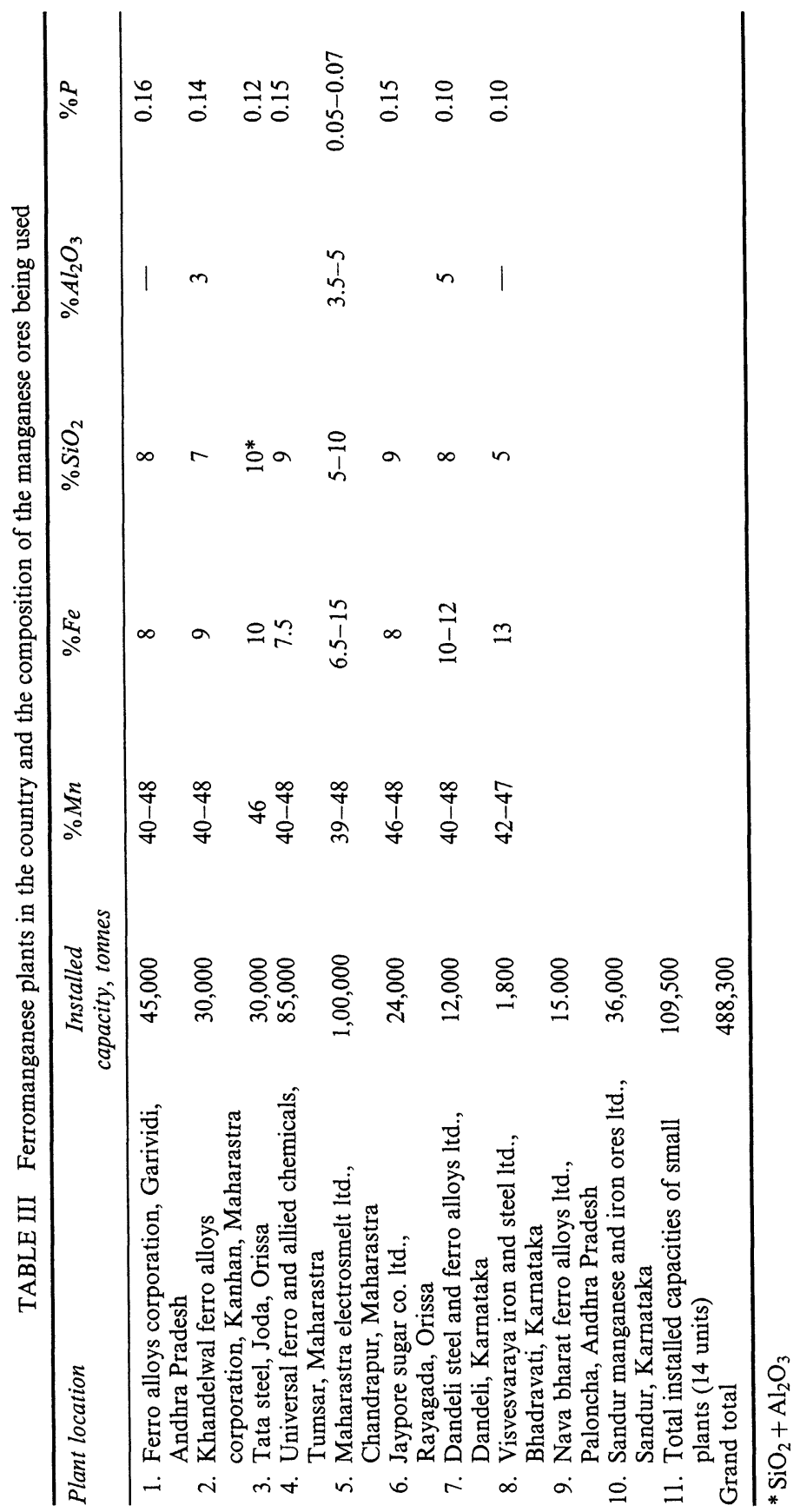


However, based on the average norm of $12 \mathrm{~kg}$ of ferromanganese/ tonne of the steel requirement, the demand for ferromanganese in steel production during 1996-97 is about 289,000 tonnes. Applying the average norm of requirement of 2.6 tonnes of manganese ore per tonne of ferromanganese the demand for high grade manganese ore is estimated at 752,000 tonnes.

The ferromanganese industry requires a manganese ore with somewhat stringent specifications demanding higher $\mathrm{Mn}, \mathrm{Mn} / \mathrm{Fe}$ ratio, lower $\mathrm{SiO}_{2}, \mathrm{Al}_{2} \mathrm{O}_{3}$ and $\mathrm{P}$ contents. The specifications of the manganese ore (IS: 4763-1982) for the manufacture of ferromanganese are 38$48 \% \mathrm{Mn}, 7-15 \% \mathrm{Fe}, 2.5-7 \mathrm{Mn} / \mathrm{Fe}$ ratio, $7.5-13 \% \mathrm{SiO}_{2}$ and $2-6 \%$ $\mathrm{Al}_{2} \mathrm{O}_{3}$ and less than $0.15 \% \mathrm{P}$. Due to the limitation of availability of such a grade of the manganese ore, currently the ores with $38 \% \mathrm{Mn}$ are being used by blending with manganese ores of $44 \%$ to $48 \% \mathrm{Mn}$. Unfortunately the total estimated recoverable reserves of the ferromanganese grade ore are only 21 million tonnes out of which only 10 million tonnes are in the proved category. With the projected demand of 0.75 million tonnes of ore per year, the reserves may last around 15 years. An immediate need of augmenting the ferromanganese grade ore reserves through exploration and upgradation of the low and medium grade ores by application of suitable beneficiation techniques thus arises.

Manganese ores of different types are distributed mostly in the states of Karnataka, Orissa, Andhra Pradesh and Maharastra. Of these, potential deposits of primary gondite types are extensively exposed in Madhya Pradesh-Maharastra region. Several open cast and under ground mines have been opened up by Manganese Ore India Ltd. (MOIL) to exploit manganese ores from many of these deposits.

This paper deals with the characterisation and beneficiation of manganese ores from Chikla deposit, of Maharastra (Fig. 1). The manganese formation of Chikla belongs to the Sausar group of rocks of Archaean age. In-depth mineralogical, petrological, genesis etc. are reported elsewhere on the ore bodies of Chikla $[4,5,6]$. The paper describes the chemical characteristics of low and medium grade manganese ores drawn from Chikla and the beneficiation studies carried out on a medium grade ore sample at the instance of MOIL. 


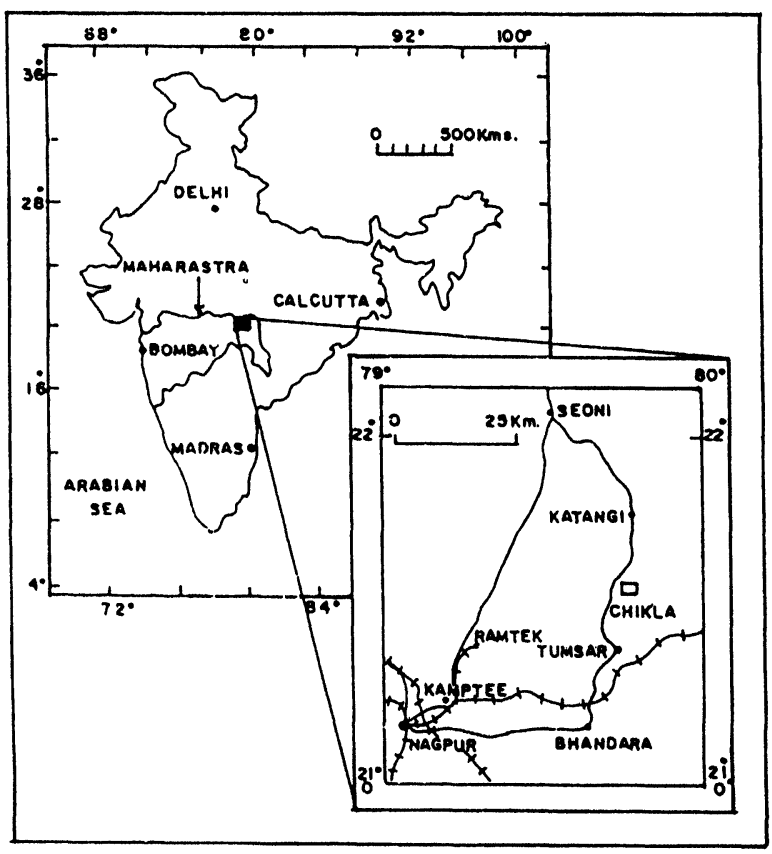

FIGURE 1 Location map of Chikla, Maharashtra.

\section{CHARACTERISATION STUDIES}

The manganese ore samples in bulk quantities were collected from various levels of the Chikla mine. The mineralogical investigations were carried out with optical microscope (Leitz-ortho plane), X-ray diffraction (Philips diffractometer) and scanning electron microscopy (Jeol, JSM 35 CF with WDS attachment). The samples were classified into various sieve fractions and each fraction was subjected to magnetic separation using isodynamic magnetic separator (with $20^{\circ}$ side tilt, $30^{\circ}$ forward slope and with the current of $0.8 \mathrm{~A}$ ). All the magnetic products of various size fractions were analysed with the help of XRF (Philips, for $\mathrm{Mn}, \mathrm{Fr}, \mathrm{Si}, \mathrm{As}, \mathrm{P}, \mathrm{S}, \mathrm{Ti}, \mathrm{Ba}, \mathrm{Mg}$ ) and flame photometer (systronics model $\mathrm{K}-111$, for $\mathrm{Na}, \mathrm{K}$, and $\mathrm{Ca}$ ) to determine the metal distribution pattern. The details are reported elsewhere [7]. However, the metal 


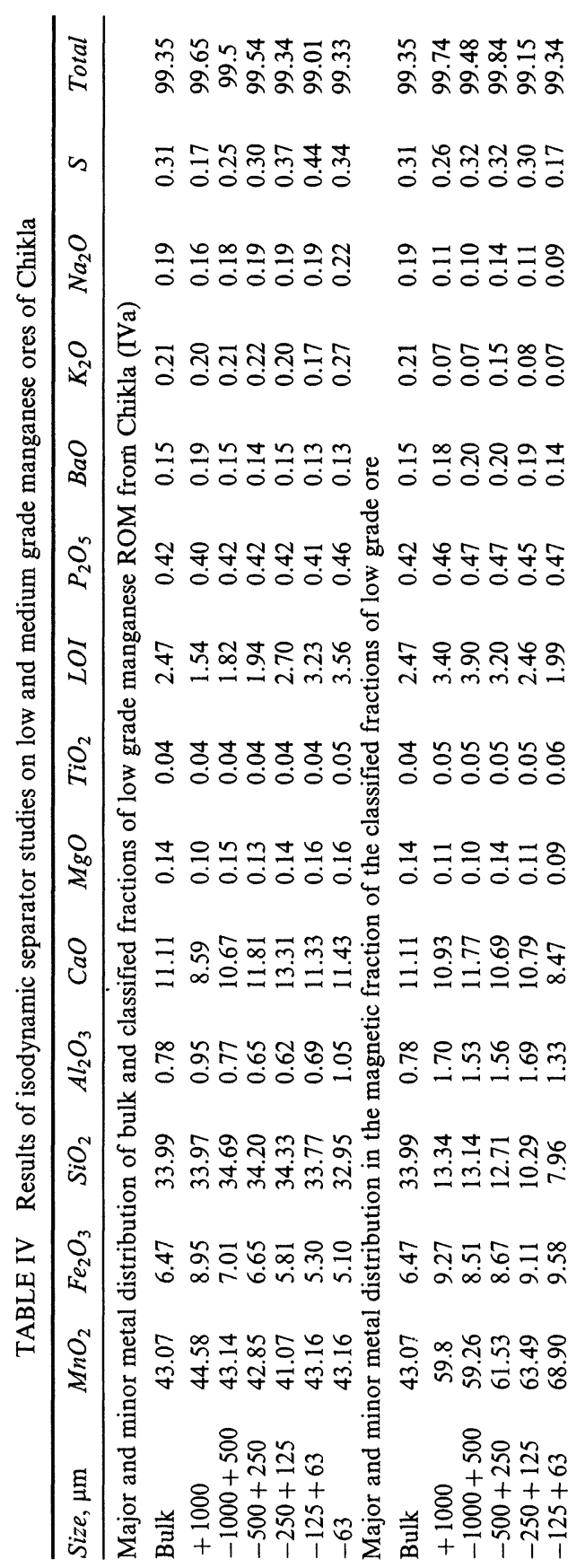




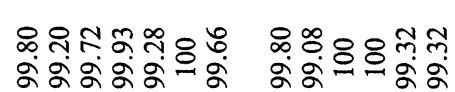

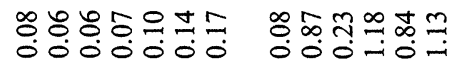

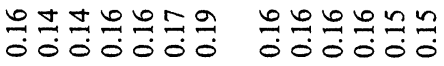

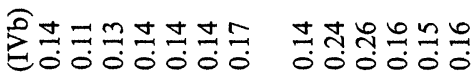
ปั

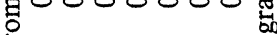

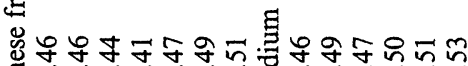
प0000000 สี फั

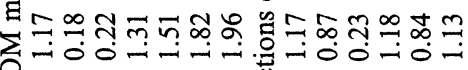
西

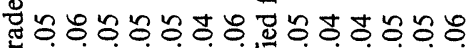

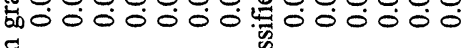
灵 贾

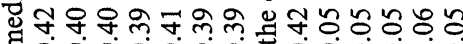
范

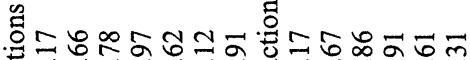

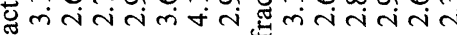

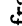

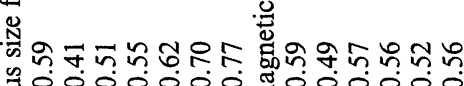

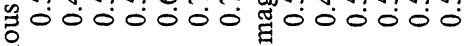
要

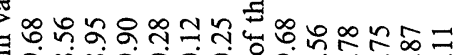
פळ@

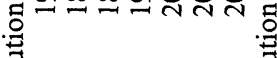

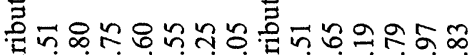
矛

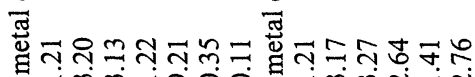

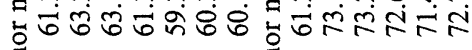
.

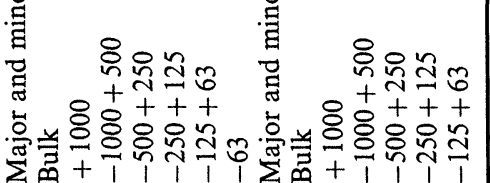


TABLE $\mathrm{V}$ Weight, $\mathrm{Mn}$ and $\mathrm{Fe}$ distribution in various size fractions of the roll crushed material

\begin{tabular}{lccccc}
\hline Size $\mu \mathrm{m}$ & $\% W t$ & $\% M n$ & $\% F e$ & \multicolumn{2}{c}{ Distribution, \% } \\
\cline { 5 - 6 } & & & & $M n$ & $F e$ \\
\hline+2000 & 47.8 & 45 & 7.8 & 48.2 & 48.3 \\
$-2000+1000$ & 21.8 & 45.6 & 7.8 & 22.4 & 22.1 \\
$-1000+420$ & 11.5 & 45.6 & 7.2 & 11.8 & 10.7 \\
$-420+210$ & 4.0 & 41.7 & 7.2 & 3.75 & 3.74 \\
$-210+105$ & 5.4 & 40.0 & 8.4 & 4.86 & 5.90 \\
-105 & 9.7 & 41.0 & 7.3 & 8.95 & 9.10 \\
Head (calc) & 100 & 44.4 & 7.69 & 100 & 100 \\
\hline
\end{tabular}

distribution pattern in low and medium grade ores are shown in Table IV.

Subsequent to these investigations, another medium grade manganese sample from the Chikla region was received from MOIL to study its amenability to beneficiation. The ore was jaw and roll crushed (at $3 \mathrm{~mm}$ rolls gap) and a representative sample was drawn for wet sieving, heavy medium and magnetic separation studies. The weight and the $\mathrm{Mn}$ and $\mathrm{Fe}$ distribution in various size fractions of the roll crushed material are given in Table V.

\section{HEAVY MEDIA STUDIES}

Various size fractions of the roll crushed material were subjected to sink and float test using an organic liquid, tetrabromoethane of specific gravity 2.96 . The heavy and light fractions were collected after washing them thoroughly with acetone and water. All the heavies and light fractions were weighed (Table VI) but not analysed for $\mathrm{Mn}$ and $\mathrm{Fe}$, since only $6 \%$ of the material resulted as the overall light fraction.

\section{MAGNETIC SEPARATION STUDIES}

\section{Wet Low Intensity Separation}

The roll crushed manganese ore was ground to below $100 \mu \mathrm{m}$ size and the ground ore was treated on SALA wet low intensity drum magnetic 
TABLE VI Distribution of heavies and lights in various sieve fractions

\begin{tabular}{lccc}
\hline Size,$\mu \mathrm{m}$ & $\% W t$ & \%Lights $($ float $)$ & \% Heavies (sink) \\
\hline+2000 & 47.6 & 3.74 & 96.26 \\
$-2000+1000$ & 21.8 & 4.38 & 95.6 \\
$-1000+420$ & 11.5 & 6.90 & 93.1 \\
$-420+210$ & 4.00 & 12.5 & 87.5 \\
$-210+105$ & 5.40 & 21.6 & 78.4 \\
-105 & 9.70 & 11.0 & 89.0 \\
\hline
\end{tabular}

Note: Overall lights fraction is $6.24 \%$ in this roll crushed material.

TABLE VII Results of magnetic studies on SALA low intensity wet magnetic separator

\begin{tabular}{|c|c|c|c|c|c|}
\hline \multirow[t]{2}{*}{ Products } & \multirow[t]{2}{*}{$\% W t$} & \multirow[t]{2}{*}{$\% M n$} & \multirow[t]{2}{*}{$\% \mathrm{Fe}$} & \multicolumn{2}{|c|}{ Distribution, $\%$} \\
\hline & & & & $M n$ & $\mathrm{Fe}$ \\
\hline Magnetic & 6.8 & 41.0 & 12 & 6.50 & 10.8 \\
\hline Middling & 2.0 & 45.6 & 7.6 & 2.10 & 2.0 \\
\hline Non-magnetic & 91.2 & 42.8 & 7.2 & 91.4 & 87.2 \\
\hline Head (calc) & 100 & 42.7 & 7.56 & 100 & 100 \\
\hline
\end{tabular}

separator. The magnetic and non-magnetic products were collected. The non-magnetic fraction was processed once again and the magnetic fraction thus obtained was considered as middling. The three products obtained on SALA low intensity magnetic separator were analysed for $\mathrm{Mn}$ and Fe (Table VII).

\section{Wet High Intensity Magnetic Separation}

The roll crushed material was further crushed by keeping the minimum possible gap between the rolls and from the resulting product a representative sample was drawn and subjected to magnetic separation on BOXMAG wet high intensity magnetic separator at $12,000 \mathrm{G}$. The roll crushed material was further ground to 30 and $60 \mathrm{~min}$ and this ground material was processed on wet high intensity magnetic separator. All the magnetic and non-magnetic products were analysed for $\mathrm{Mn}$ and $\mathrm{Fe}$ (Table VIII).

Another set of studies was carried out on this ground product by varying the intensity, so as to ascertain the optimum conditions and the products were analysed for Mn and Fe (Table IX). 
TABLE VIII Results of magnetic separation on BOXMAG wet high intensity magnetic separator

\begin{tabular}{llccccc}
\hline Code & Products & $\% W t$ & $\% M n$ & $\% F e$ & $M n / F e$ & $\begin{array}{c}\text { Distribution, \% } \\
M n\end{array}$ \\
\hline A & Magnetic & 88.5 & 46.8 & 8.9 & 5.4 & 93 \\
& Non-magnetic & 11.5 & 28.5 & 6.1 & & 7 \\
B & Magnetic & 77 & 50.5 & 8.6 & 5.87 & 87 \\
& Non-magnetic & 23 & 24.7 & 5.0 & & 13 \\
C & Magnetic & 74.2 & 51.1 & 8.8 & 5.37 & 85 \\
& Non-magnetic & 25.8 & 26.6 & 6.0 & & 15 \\
\hline
\end{tabular}

A: Roll crushed material with $\mathrm{d}_{80} \sim 600 \mu \mathrm{m}$.

B: 30 min. ground product with $\mathrm{d}_{80} \sim 100 \mu \mathrm{m}$.

C: 60 min ground product with $\mathrm{d}_{80} \sim 60 \mu \mathrm{m}$.

TABLE IX Results of magnetic separation on BOXMAG wet high intensity magnetic separator (at various field strength)

\begin{tabular}{|c|c|c|c|c|c|c|}
\hline Intensity, $\mathrm{G}$ & Products & $\% W t$ & $\% M n$ & $\% \mathrm{Fe}$ & $\mathrm{Mn} / \mathrm{Fe}$ & $\begin{array}{c}\text { Distribution, } \% \\
M n\end{array}$ \\
\hline \multirow[t]{2}{*}{12,000} & Magnetic & 74.2 & 51.1 & 9.0 & 5.37 & 85 \\
\hline & Non-magnetic & 25.8 & 26.4 & 6.1 & & 15 \\
\hline \multirow[t]{2}{*}{15,000} & Magnetic & 81.2 & 51.0 & 8.9 & 5.73 & 95 \\
\hline & Non-magnetic & 18.8 & 15 & 3.4 & & 5 \\
\hline \multirow[t]{2}{*}{18,000} & Magnetic & 84.6 & 51.1 & 8.9 & 5.74 & 96 \\
\hline & Non-magnetic & 15.4 & 11.0 & 2.8 & & 4 \\
\hline
\end{tabular}

\section{RESULTS AND DISCUSSION}

The high grade material suitable for ferromanganese production is limited (Table I), although the country has vast resources of the manganese ores. The ferromanganese industry in the country is likely to be affected due to this and it calls for an urgent need to augment the ferromanganese grade reserves. In Maharastra MOIL operates manganese mines both open cast and underground mining. The manganese ores mined from Chikla region contain mostly low grade to medium grade type ores.

Mineralogical studies on various grade ores drawn from Chikla revealed the presence of manganese minerals in three predominant forms: manganese oxides, manganese silicates and as manganese carbonates, while iron is present as hematite and goethite. Braunite, bixbyte, husmannite, jacobsite and coronadite form the major primary oxides, while pyrolusite, cryptomalene and psilomalane are recorded as 
secondary oxide minerals. The manganese silicate phases are represented by hedenbergite, spessartite and rhodonite while kutnohorite and rhodocrosite form the carbonates. The gangue minerals mainly include silicates, carbonates, phosphates and sulphate. The silicate minerals occur in a close association with the manganese minerals. The XRD pattern of a medium grade ore sample is illustrated in Fig. 2. Quartz, orthoclase, plagioclase and diopside together form a major portion of the gangue minerals. Calcite and barite appear to be associated with manganese and silicate phases. Calcite occurs as secondary veins. Electron microscopic studies through X-ray image mapping revealed these veins to be rich in phosphorus. The phosphorus content in the ores from Chikla is relatively low and well within the range needed by ferromanganese industry. However, minute grains of manganese minerals within silicates and similar silicate grains within manganese phases pose problems in their liberation.

The distribution of different elements in various size fractions in low grade (Table IVa) and medium grade (Table IVb) run of mine samples

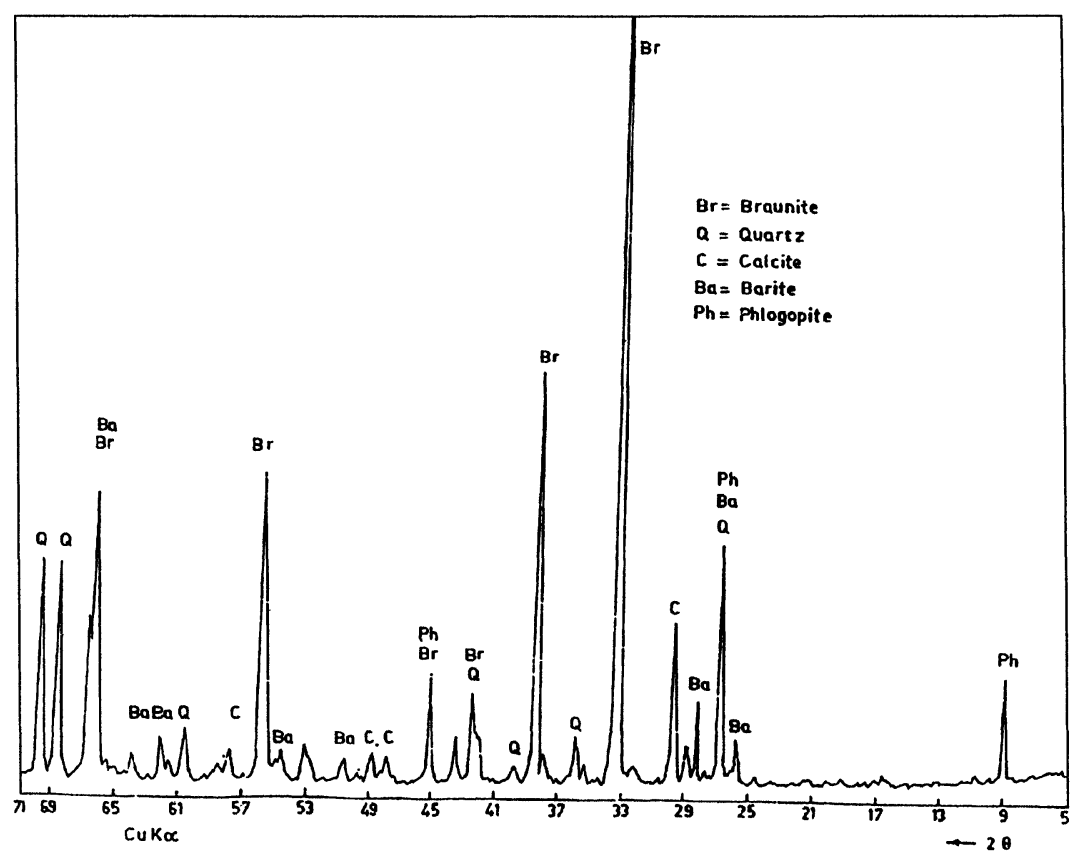

FIGURE 2 XRD pattern of medium grade manganese ore from Chikla 
are given in Table IV. These samples were subjected to isodynamic separation and the magnetic products of corresponding fractions were analysed. The analyses indicated substantial improvement in the quality of the magnetic fractions which is largely due to the rejection of silica and calcia content, in addition to the high magnetic susceptibility of the manganese bearing minerals like braunite, bixbyte and husmannite. As the major gangue minerals are quartz and calcium carbonates, the enrichment of manganese by magnetic separation technique may be the ideal process to upgrade the manganese ores of Chikla region.

Another medium grade ore sample ( $44 \% \mathrm{Mn}, 7.7 \% \mathrm{Fe}$, with $20-22 \%$ acid insolubles) from the Chikla region was studied for its amenability to beneficiation at the instance of MOIL. The preference of MOIL is to study its response to beneficiation by jigging. Table $\mathrm{V}$ indicates the distribution pattern of $\mathrm{Mn}$ and $\mathrm{Fe}$ in various sieve fractions of the roll crushed material ( $3 \mathrm{~mm}$ rolls gap). The sink and float studies on the size fractions using tetrabromoethane reveal (Table VI) that only $6-7 \%$ of the material could be obtained as light fraction which means $6-7 \%$ of the material only can be rejected theoretically by jigging. In case the material is subjected to jigging the manganese content can only be raised to around $47 \% \mathrm{Mn}$, as against the theoretical possibility of around $55 \%$ Mn by rejecting the $20 \%$ acid insolubles. Hence the application of jigging to such ores is not considered as a pragmatic approach.

It can be seen from Table VII that the manganese minerals are not prone to enrichment by wet low intensity magnetic separation on SALA drum magnetic separator. As the isodynamic separation studies on a similar medium grade ore revealed its susceptibility to the manganese enrichment, studies were carried out on BOXMAG wet high intensity magnetic separator. Table VIII indicates the possibility of enriching the $\mathrm{Mn}$ content to around $51 \%$ with $85 \%$ recovery. However, the ore needs to be ground to below $100 \mu \mathrm{m}$ size. Studies carried out by varying the field strength revealed that around $15,000 \mathrm{G}$ may be adequate to enrich the Mn content to around $51 \% \mathrm{Mn}$ with $95 \%$ recovery, which is very close to the theoretically possible enrichment value. As the manganese ores from the Chikla region are the low phosphorus bearing ores, the beneficiated ore can be a potential resource for the ferromanganese industry. 


\section{CONCLUSIONS}

The manganese ores from Chikla region are by and large of low to medium grade type and low in phosphorus content. Isodynamic separation studies on various ores from this region revealed their susceptibility to high intensity magnetic separation due to the presence of some manganese oxide minerals (bixybite, braunite, husmannite) along with quartz and calcite as major gangue.

The characterisation and beneficiation studies on a medium grade manganese ore sample from Chikla containing $44 \% \mathrm{Mn}, 7.9 \% \mathrm{Fe}$ and $20-22 \%$ acid insolubles revealed that the manganese content can be raised to around $47 \% \mathrm{Mn}$ by jigging, whereas by grinding the ore to below $100 \mu \mathrm{m}$ size followed by treatment on wet high intensity magnetic separator the Mn content can be enriched to $51 \%$ Mn with $95 \%$ recovery. This material having $\mathrm{Mn} / \mathrm{Fe}$ ratio 5.7 with low phosphorus can be a potential resource for the ferromanganese industry.

\section{Acknowledgements}

The authorities of MOIL are duly thanked for supplying the necessary manganese ores from Chikla region. The authors are grateful to Prof. H.S. Ray, Director, Regional Research Laboratory, Bhubaneswar for permission to publish this paper. The analytical assistance by Dr. P. Chattopadhyay, scientist, and Sri. S. Misra, junior project assistant, is acknowledged.

\section{References}

[1] Reddy, A.J. An overview of manganese ore and alloys industry in India in a global perspective. In seminar volume on "Manganese - Ores and Alloys", Dec 8-9, Bhubaneswar, 1995, pp. 147-160.

[2] Thakore, R. Manganese ore - An over view: In seminar volume on "Manganese Ores and Alloys", Dec 8-9, Bhubaneswar, 1995, pp. 207-215.

[3] Khuntia, G.S.S Demand pattern of manganese ore for Iron \& Steel industry of India with special emphasis on SAIL, now \& tomorrow. In seminar volume on "Manganese - Ores and Alloys" Dec 8-9, Bhubaneswar, pp. 191-196.

[4] Bilgrami, S.A. Manganese amphiboles from Chikla, Bhandara dist., India. Min. Mag. 30, 1955, pp. 633-644.

[5] Dasgupta, S., Fukuora, M. and Roy, S. Hematite-pyrophanite intergrowth in gondite, Chikla area, sausar group. Ind. Min. Mag. 48, 1984, pp. 558-560. 
[6] Mitra, F.N. Genessis and mineralogical trend of the manganese ore bodies at Chikla, Sitasongi and Dongri Buzurg, Bhandara dist., Maharastra, India. Econ. Geol., 60, 1965, pp. 299-316.

[7] Mahapatra, B.K., Rao, D.S. and Sahu, R.K. Characterisation and magnetic separation studies of Chikla manganese ores, Maharastra. Ind. Min. Eng. J. July, 1995, pp. 37-41.

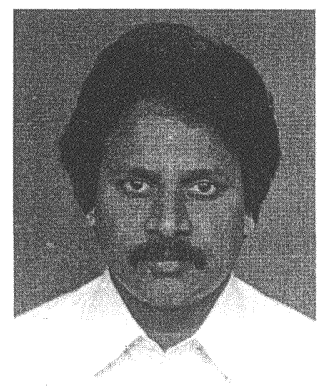

G.V. Rao is the senior scientist at Regional Research Laboratory, Bhubaneswar, India. He has one year teaching and 18 years research experience in the field of mineral processing. Mr. Rao received his B. Tech. (Chem. Engg.) and M.Sc. (Mineral Processing Engineering) degrees from Andhra University, College of Engineering, Visakhapatnam, India, and has published around 30 articles in various national and international journals.

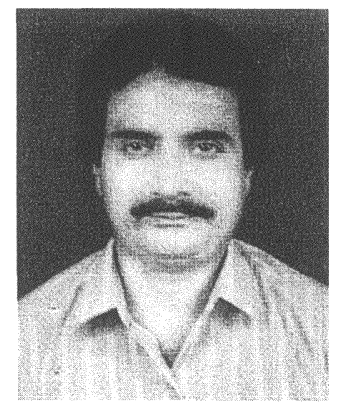

B.K. Mohapatra obtained Ph.D. in mineralogy from Utkal University, Orissa, India. Before joining the Regional Research Laboratory (CSIR) in Bhubaneswar as a scientist in 1981, he was employed for several years by the Geological Survey of India as a geologist. His current field of research is the mineralogical characterisation of ore minerals, slags, sinters and leach residues.

A.K. Tripathy graduated in metallurgical engineering from Ravishankar University, Raipur, India, and obtained the M. Engg. degree in extractive metallurgy from the the University of Roorkee. He also obtained his Ph.D. in metallurgical engineering from the Indian Institute of Technology, Bombay. Dr. Tripathy is now a senior scientist at the Pyrometallurgy Division of the Regional Research Laboratory which he joined in 1973. 